\title{
Application of \\ Fourier Transform Infrared Evolved Gas Analysis (FT-IR-EGA) to the Study of Tobacco Curing *
}

\author{
by Robert A. Fenner, Jim Lyons-Hart, John O. Lephardt and Daniel M. Teng
}

Philip Morris Research Center, Richmond, Virginia, U.S.A.

\section{SUMMARY}

FT-IR evolved gas analysis, a non-isothermal pyrolysis technique, is used to probe the changes in tobacco leaf composition which occur during flue and air curing. A unique perspective of major enzymatic processes and their dependencies on curing method is obtained through simultaneous detection of multiple pyrolytic products and three-dimensional presentation of the product evolution profiles. The conversion of starch to sugars, proteins to amino acids, and the relationships between these processes are explored.

\section{ZUSAMMENFASSUNG}

Unter Einsatz der FT-IR-Gasanalyse, ein nichtisothermes Pyrolyseverfahren, wurde untersucht, inwieweit die Trocknungsverfahren "flue curing ${ }^{\alpha}$ und , air curing zu Verānderungen der chemischen Zusammensetzung des Tabakblattes führen. Das gleichzeitige Erfassen vieler verschiedener Pyrolyseprodukte und deren dreidimensional dargestellten Entwicklungsprofile vermitteln bemerkenswerte Einblicke in wichtige enzymatische Vorgānge und deren Abhängigkeit von der Art der Trocknung. Besondere Aufmerksamkeit wurde der Umwandlung von Stärke zu Zucker und von Proteinen $\mathrm{zu}$ Aminosăuren sowie den zwischen diesen beiden Umsetzungsprozessen bestehenden Wechselwirkungen gewidmet.

\footnotetext{
* Received: 7th May 1987 - aecepted: 26th April 1988.
}

\section{RESUME}

L'analyse en phase gazeuse FT-IR (transformation de Fourier), une technique de pyrolyse non isotherme, a été mise en œuvre pour étudier dans quelle mesure les procédés de séchage *flue curing» et *air curing* entraînaient des modifications de la composition chimique des feuilles de tabac. La détection simultanée d'un grand nombre de produits de pyrolyse différents et $l_{2}$ représentation en trois dimensions de leurs profils d'évolution ont fourni un remarquable aperçu des processus enzymatiques majeurs ainsi que de leur dépendance de la méthode de séchage utilisée. Une attention particulière a été accordée à la transformation de l'amidon en sucre et à celle des protéines en acides aminés ainsi qu'à l'interdépendance de ces deux processus.

\section{INT'RODUCTION}

Tobacco curing practices are complex processes which control biochemical reactions to obtain a tobacco leaf with desirable smoke qualities. To understand the changes in tobacco composition which accompany curing requires analytical techniques capable of providing information about the biopolymers (e.g. carbohydrates and proteins) and related materials involved in these reactions. Traditionally, chemical and physical separations have been used to obtain this information. These procedures; however, are often tedious and very time-consuming. In addition, chemical separations in- 
herently have the potential to change the characteristics of materials. Thermal methods of analysis offer an alternative approach to examine complex materials.

When a complex natural product such as tobacco is heated, constituents which differ in physical and/or chemical characteristics will decompose at different temperatures and yield different products or a different distribution of products. Thus, a separation or discrimination of constituents can be effected through the kinetics of thermal decomposition. A variety of pyrolysis techniques have been developed that capitalize on this approach. One such method is Fourier transform infrared (FT-IR) evolved gas analysis (1-3). This technique affords the ability to detect and to monitor multiple decomposition volatiles, continuously, as a sample is heated under controlled and reproducible conditions. The application of FT-IR evolved gas analysis to investigate compositional changes in Nicotiana tabacum L. cv. Coker 319 during flue and air curing is the focus of this study.

\section{EXPERIMENTAL}

\section{FT-IR Evolved Gas Analysis}

The instrumentation and methodology used to perform FT-IR evolved gas analysis have been previously reported $(1,2)$. An in-depth discussion of the design and the experimental considerations of the system also may be found in a recent review article (3).

For the evolved gas analysis of the tobaccos in this study, a $1.00 \mathrm{~g}$ sample ground to pass through a 20 mesh sieve was pyrolyzed from ambient to approximately $800^{\circ} \mathrm{C}$. Pyrolysis was performed with a programmed heating rate of $5 \% / \mathrm{min}$ with $60 \mathrm{ml} / \mathrm{min}$ of nitrogen carrier gas.

\section{Tobacco Sampling}

The tobacco, Coker 319, was field grown according to conventional practices for bright tobacco. One section of plants was handled in normal fashion with sequential primings. When ripe, the middle one-third of the plant leaves was primed and flue cured. A second section of

Table 1.

Sampling times of Coker $\mathbf{3 1 9}$ during flue and alr curing.

\begin{tabular}{l|l}
\hline Flue curing & Air curing \\
\hline Mature green leaf & Mature green leaf \\
At yellowing $(96 \mathrm{~h})$ & At one week \\
At fixing $(144 \mathrm{~h})$ & At two weeks \\
End of cure $(168 \mathrm{~h})$ & At four weeks \\
& At six weeks \\
& End of cure \\
\hline
\end{tabular}

plants which had not been subjected to priming was stalk cut and air cured. Samples of leaf were taken at specific times (Table 1) during each curing process and were freeze dried. Freeze drying was used to halt the effects of curing at the time of sampling. Mid-stalk samples were selected for analysis.

\section{RESULTS AND DISCUSSION}

\section{Carbobydrates}

Carbohydrates are the most abundant form of organic matter present in plant tissues. In tobacco, carbohydrates including free sugars, storage polysaccharides (e.g. starch) and structural polysaccharides (e.g. cellulose) can contribute up to $50 \%$ of the green leaf dry weight. To explore how these components respond during flue and air curing, evolved gas analysis (EGA) profiles for water, furfural, formic acid, and methanol were examined.

Figure 1 shows the pyrolysis profiles of evolved water versus temperature for the Coker 319 at progressive stages of each cure. The primary transition in the two mature green leaf samples arises from starch at $-285^{\circ} \mathrm{C}$. Shortly after the initiation of both curing processes, there is a significant decrease in this transition. Coupled

\section{Flgure 1.}

Pyrolytic evolution profiles of water versus temperature from Coker 319 at progressive stages of flue und alr curing (heating rate: $5^{\circ} \mathrm{C} / \mathrm{min}$, flow rate of $\mathrm{N}_{2}: 60 \mathrm{ml} / \mathrm{min}$ ).
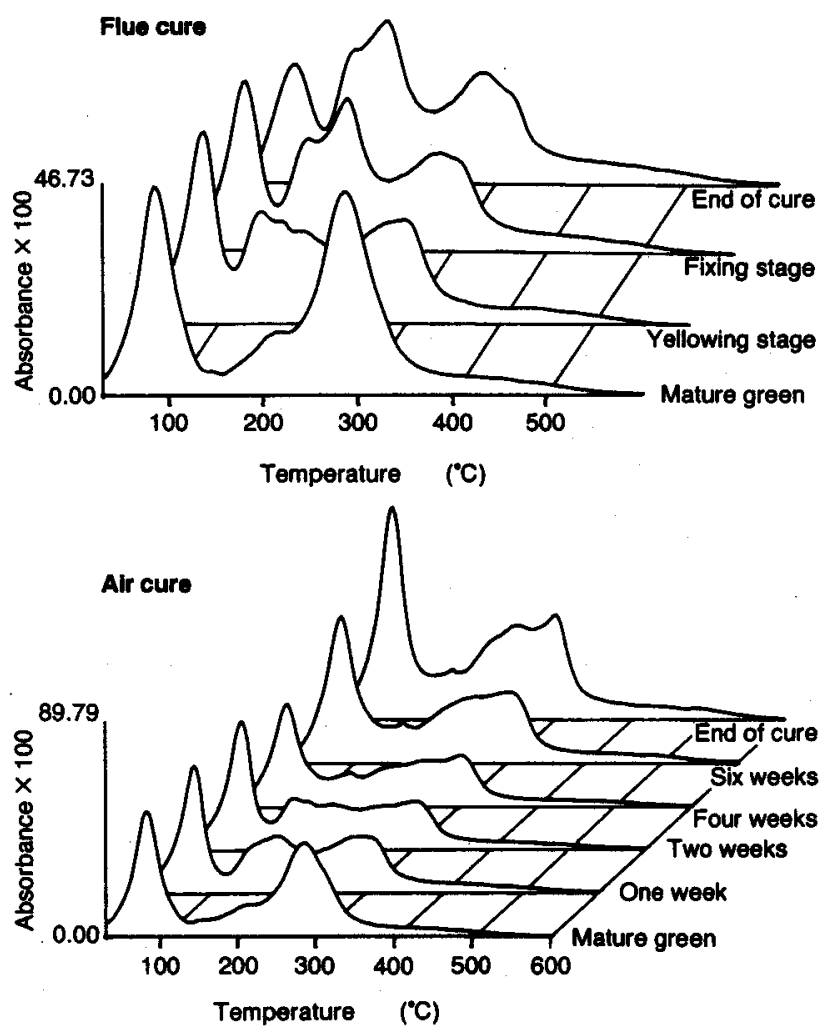
with this loss is the appearance at lower temperatures of multiple transitions with peak maxima near $150^{\circ} \mathrm{C}$, $170^{\circ} \mathrm{C}$, and $190^{\circ} \mathrm{C}$. During subsequent stages of flue curing, this region continues to increase and a transition at $180^{\circ} \mathrm{C}$, characteristic of simple sugars, becomes dominant. For the air-cured material, the trend is reversed. The $150^{\circ} \mathrm{C}$ and $190^{\circ} \mathrm{C}$ regions begin to decrease at two weeks and become minimal after six weeks of curing.

The changes observed in the early phases of both curings can be explained by the known enzymatic hydrolysis of the green leaf starch components. The formation of materials which decompose below $200^{\circ} \mathrm{C}$ is characteristic of the products from this process. Starch, present in significant quantity in the green leaf, may consist of the linear polymer amylose ( $\alpha-1,4$ linkages of glucose) and the branched polymer amylopectin $(\alpha-1,4$ and $\alpha-1,6$ linkage). Depending upon the enzymes present and their specificity for attacking $\alpha-1,4$ and $\alpha-1,6$ linkages, a variety of products can be formed initially during hydrolysis. These may include mono-, di- and oligosaccharides. All of these lower molecular weight materials would decompose during pyrolysis at lower temperatures than the parent starch. The ultimate end products of starch hydrolysis are simple sugars, principally D-glucose. These materials are clearly retained in

Figure 2.

Pyrolytic evolution profiles of furfural versus temperature from Coker 319 at progreesive stages of flue and air curing (heating rate: $5^{\circ} \mathrm{C} / \mathrm{min}$, flow rate of $\mathrm{N}_{2}: 60 \mathrm{ml} / \mathrm{min}$ ).
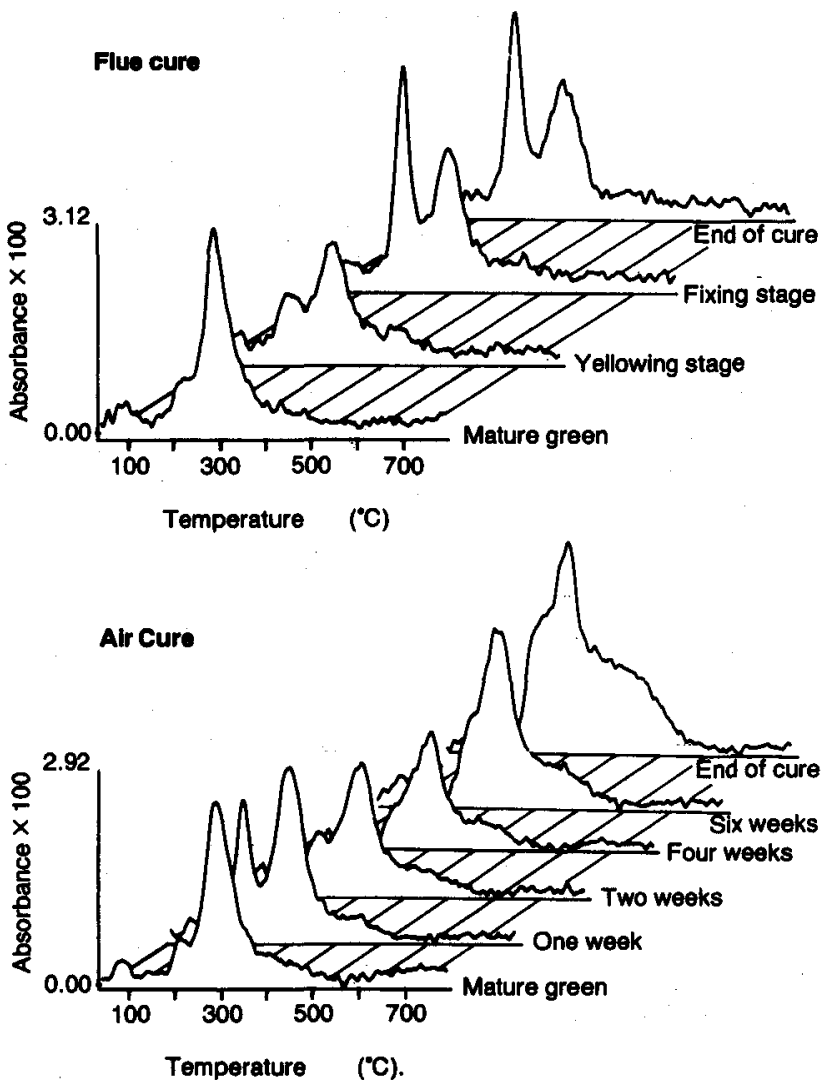

significant quantity in the leaf at the end of flue curing. The air-curing process, however, appears more complex. While starch hydrolysis products are suggested initially, these materials are subsequently metabolized or modified.

Pyrolysis products more specific to carbohydrates permit a closer inspection of the differences suggested in the water data. Furfural (2-furaldehyde) is a volatile product formed from the dehydration of simple sugars (pentoses) and can also arise during thermal depolymerization of polysaccharides. The evolution profiles for this component are shown in Figure 2. Starch enzymolysis is much more readily observed in these data. In the case of flue curing, most of the free sugars can be seen to accumulate in the leaf during the fixing stage. This probably results from reduced respiration demand on these materials during this stage along with continued starch hydrolysis. It is believed that the enzymatic respiration mechanism involved has some heat sensitivity such that the higher temperatures used during fixing are destructive to the process. Continued high temperature drying of the leaf after the fixing stage appears to have no additional effect on the sugar content. The transition that appears at $\sim 310^{\circ} \mathrm{C}$ arises primarily from cellulose. For the air-cured samples, there is an appreciable accumulation of sugars from starch hydrolysis after one week of curing, but this declines rapidly thereafter. In the more lengthy process of

Figure 3.

Pyrolytic evolution profiles of formic acld versus temperature from Coker 319 at progresslve stages of flue and alr curing (heating rate: $5^{\circ} \mathrm{C} / \mathrm{min}$, flow rate of $\mathrm{N}_{2}: 60 \mathrm{ml} / \mathrm{min}$ ).
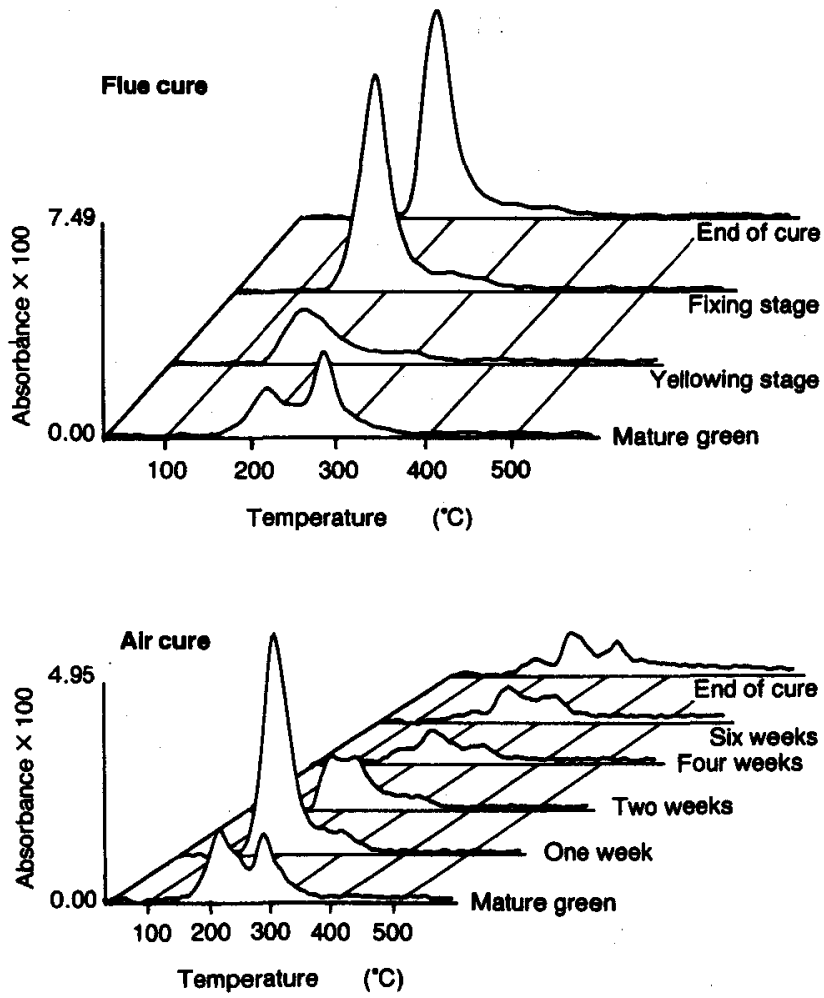
Figure 4.

Pyrolytic evolution proflles of formic acid versus temperature from Coker 319 at progressive stages of air curing (heating rate: $5^{\circ} \mathrm{C} / \mathrm{min}$, flow rate of $\mathrm{N}_{2}: 60 \mathrm{ml} / \mathrm{min}$ ).

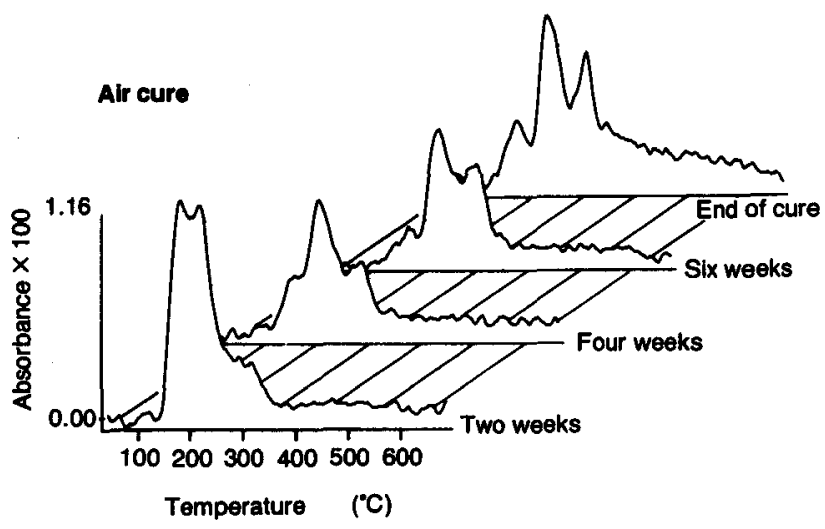

air curing, elevated temperatures are not employed, desiccation occurs more slowly and respiration could be prolonged. This could account for the observed loss of sugars. There are, in addition, changes in the relative amounts of furfural at higher pyrolysis temperatures as air curing proceeds. The first area of change centers around $240^{\circ} \mathrm{C}-$ a region normally associated with pectins and hemicellulose. The second area of change covers a much broader temperature range maximizing between $350^{\circ} \mathrm{C}$ and $550^{\circ} \mathrm{C}$. It is interesting that this temperature range is significantly higher than that observed for most polysaccharides including cellulose. This may suggest the formation of even more complex, high molecular weight carbohydrates or the incorporation of carbohydrate moieties by other components of greater thermal stability. Perhaps the sugars released by starch hydrolysis are also consumed by processes to form these more complex materials.

Further insight into the distribution of tobacco polysaccharides, including the average degree of polymerization $[\overline{\mathrm{DP}}]$ and chain branching, can be obtained from the formic acid profiles (Figure 3). On first inspection, the profiles for both cures appear only to confirm the presence of free sugars by the $180^{\circ} \mathrm{C}$ transition. In previous studies it has been proposed that formic acid is a product specific not only to free sugars but also to terminal sugar units in polysaccharides (2). Thus; the smaller formic acid transitions above $200^{\circ} \mathrm{C}$ which arise from these higher molecular weight components may be very informative. For the air-cured tobacco, these transitions are most visible from two weeks until the end of curing as illustrated in Figure 4. A ratio of the amount of formic acid to that of a more general pyrolysis product (e.g. water or furfural) should provide a means of comparing the relative size and complexity of

Figure 5.

Pyrolytic evolution profiles of formic acid $(-)$ and furfural $(. .$.$) versus temperature$ from flue and air-cured Coker 319 (heating rate: $5^{\circ} \mathrm{C} / \mathrm{min}$, flow rate of $\mathrm{N}_{2}: 60 \mathrm{ml} / \mathrm{min}$ ).
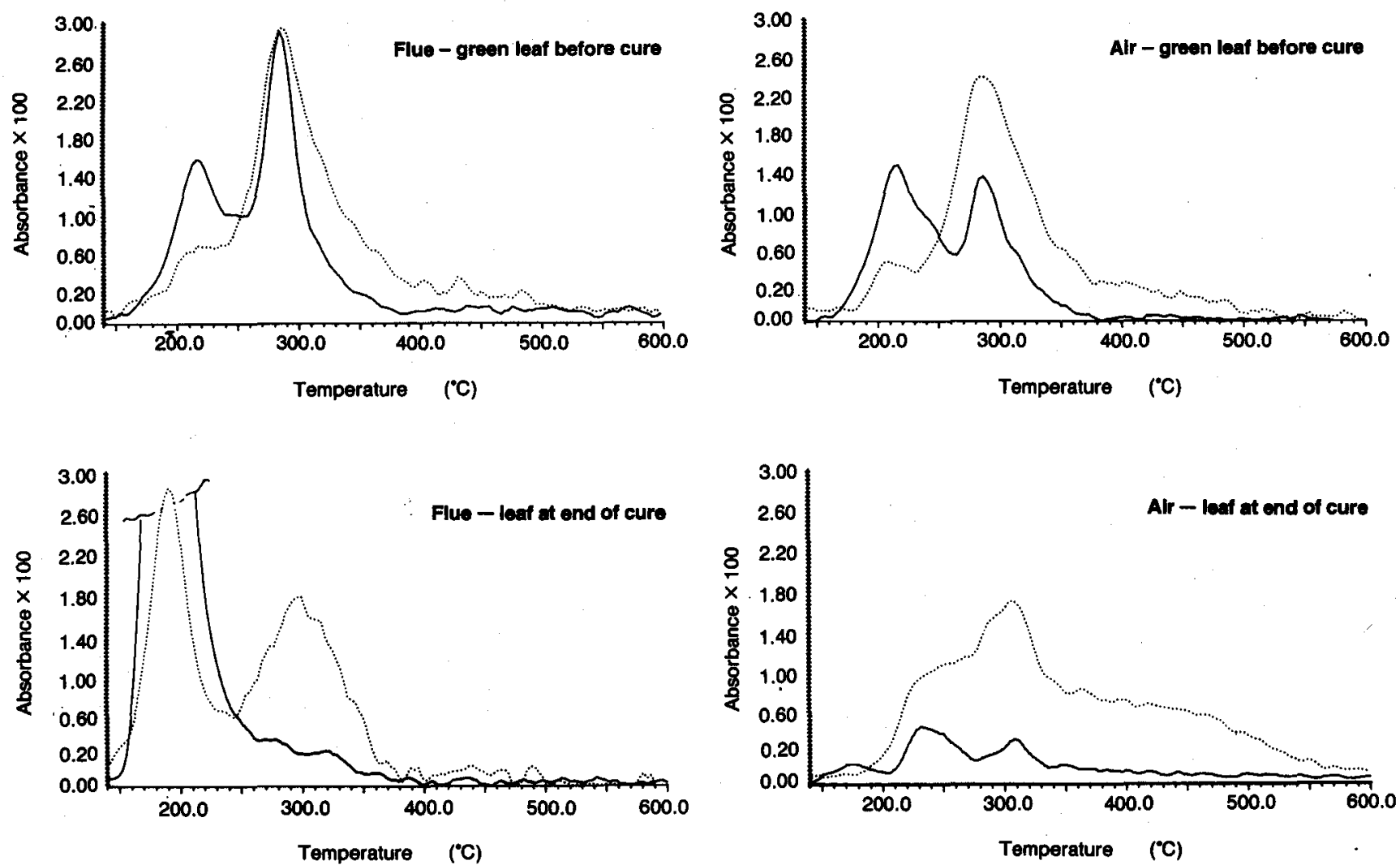
the polysaccharides. Shown in Figure 5 are the formic acid and furfural profiles for the mature green leaf and cured leaf samples. In this comparison, the $\sim 40 \%$ difference in weight loss reported between flue and air curing has been taken into account by scaling the end of cure profiles.

Beginning with the green leaf state, there are apparent differences in the starch components $\left(290^{\circ} \mathrm{C}\right.$ transition) between the primed leaf (flue cure) and stalk-cut leaf (air cure). The profiles for the primed leaf indicate a slightly higher starch content. More interestingly, they reveal a structurally dissimilar starch compared to that of the stalk-cut leaf. The larger ratio of formic acid to furfural (1.0 vs. $\sim 0.5)$ suggests a greater number of terminal glucosides. This could result from a larger percentage of amylopectin (branched form of starch) and/ or 2 shorter average chain length (smaller DP) in the starch components. This disparity may simply reflect a difference in the degree of maturity between the samples at the time of harvest. Both of the green leaf samples also contain some simpler carbohydrates indicated by the transitions around $200^{\circ} \mathrm{C}$. These components may be small oligosaccharides or free sugars based upon the larger amount of formic acid relative to furfural.

At the termination of curing when most of the starch has been consumed, underlying transitions characteristic of other polysaccharides become more visible. Cellulose, the primary structural component of plant cell

\section{Figure 6.}

Pyrolytic evolution profiles of methanol versus temperature from flue-cured $(-)$ and alr-cured (...) Coker 319 (heating rate: $5^{\circ} \mathrm{C} / \mathrm{min}$, flow rate of $\mathrm{N}_{2}: 60 \mathrm{ml} / \mathrm{min}$ ).
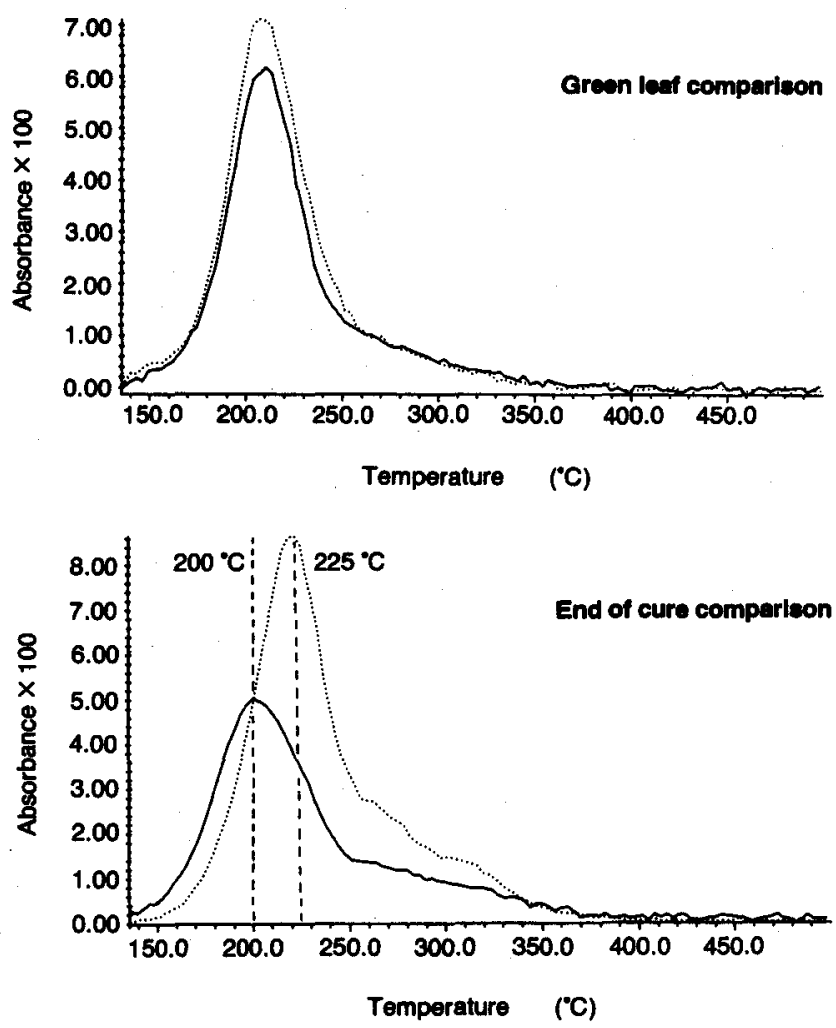

wall, can be observed at $\sim 315^{\circ} \mathrm{C}$. The amount and relative molecular weight (also molecular complexity) of this component appear comparable in the flue and aircured leaf. Both of the cured samples appear to have retained some starch evidenced by the transition between $\sim 270^{\circ} \mathrm{C}$ and $295^{\circ} \mathrm{C}$. As noted earlier, pectins and hemicellulose show major decomposition in the $200^{\circ} \mathrm{C}$ to $270^{\circ} \mathrm{C}$ region. Although this area is partially obscured in the flue-cured sample by the $180^{\circ} \mathrm{C}$ sugar transition, the formic acid/furfural ratio appears different from that of the air-cured material. By using the arguments applied previously, the comparative data indicate the air-cured components may be of higher molecular weight.

The group of polysaccharides collectively identified as pectic substances are polymers consisting of galacturonic acid units. Differentiation among the biopolymers in this group is based upon water solubility and the extent of methylation of the acid groups. Based on the analysis of standard materials, methylated pectins are a major contributor of pyrolytic methanol evolution in tobacco and this evolution is observed at approximately $200^{\circ} \mathrm{C}$. Comparative methanol profiles for the green leaf and end of cure samples are shown in Figure 6. Before curing, the methanol arising from the pectins $\left(-210^{\circ} \mathrm{C}\right)$ in the primed and stalk-cut green leaf appears almost identical. At the end of curing, the pectin transitions for the two processed samples bear much less resemblance to one another. The peak maximum for the air-cured leaf is shifted to a higher temperature around $225^{\circ} \mathrm{C}$. For the flue-cured leaf, the major peak appears lowered in temperature (to $\sim 200^{\circ} \mathrm{C}$ ) but exhibits a small shoulder at $225^{\circ} \mathrm{C}$. In the context of the formic acid / furfural data, this difference in methylated pectins may be one of molecular weight. The flue-cured leaf may contain methylated pectins primarily of lower molecular weight with a small percentage of high molecular weight material. Air-cured leaf, on the other hand, may contain the higher molecular weight methylated pectins almost exclusively. What role the reported association of pectin with calcium might play in affecting this distribution is difficult to assess.

\section{Proteins and Amino Acids}

The changes which occur in the nitrogenous components of tobacco during curing are important in determining the overall quality of the processed leaf. In addition to the alkaloids, proteins and amino acids have received considerable attention in curing studies. By using evolved gas analysis to profile decomposition products specific to amino acids and proteins, some description of their behavior during curing is possible.

Shown in Figure 7 are the ammonia evolution profiles for the flue and air-cured samples. The sequential profiles for flue curing indicate that rather few changes accompany this treatment. There is an initial increase, during yellowing, in the level of ammonia precursors between $225^{\circ} \mathrm{C}$ and $\sim 400^{\circ} \mathrm{C}$. Evolution in this region 
is then seen to decrease during subsequent stages. In the air-curing treatment, more complex changes are apparent and at the end of curing the ammonia profile is significantly altered from that of the green leaf. The most dramatic of the changes is the appearance of an ammonia peak at $190^{\circ} \mathrm{C}$ which is not observed with flue curing. In the $225^{\circ} \mathrm{C}$ to $400^{\circ} \mathrm{C}$ region, the ammonia levels appear to intensify especially in the lower portion of this temperature range. While it is not possible to directly relate specific precursors with distinct ammonia transitions, some generalizations can be made about particular regions in the profiles. Studies of model compounds suggest that the $225^{\circ} \mathrm{C}$ to $350^{\circ} \mathrm{C}$ region of the ammonia profile may be attributed to amino acid decomposition and $350^{\circ} \mathrm{C}$ to $475^{\circ} \mathrm{C}$ to protein decomposition. Based on this information, the ammonia profiles for flue curing suggest that amino acids increase significantly during the yellowing stage. This observation is consistent with the reported enzymatic degradation of protein (proteolysis) to form amino acids attendant with the yellowing process (4). It has also been observed that the amino acid levels decline, presumably through oxidative deamination, as flue curing proceeds to completion (5). The ammonia profiles for the fixing and the final drying stages are in agreement with this finding. When the bright tobacco is subjected

Figure 7.

Pyrolytic evolution profiles of ammonia versus temperature from Coker 319 at progressive stages of flue and alr curing (heating rate: $5^{\circ} \mathrm{C} / \mathrm{min}$, flow rate of $\mathrm{N}_{2}: 60 \mathrm{ml} / \mathrm{min}$ ).
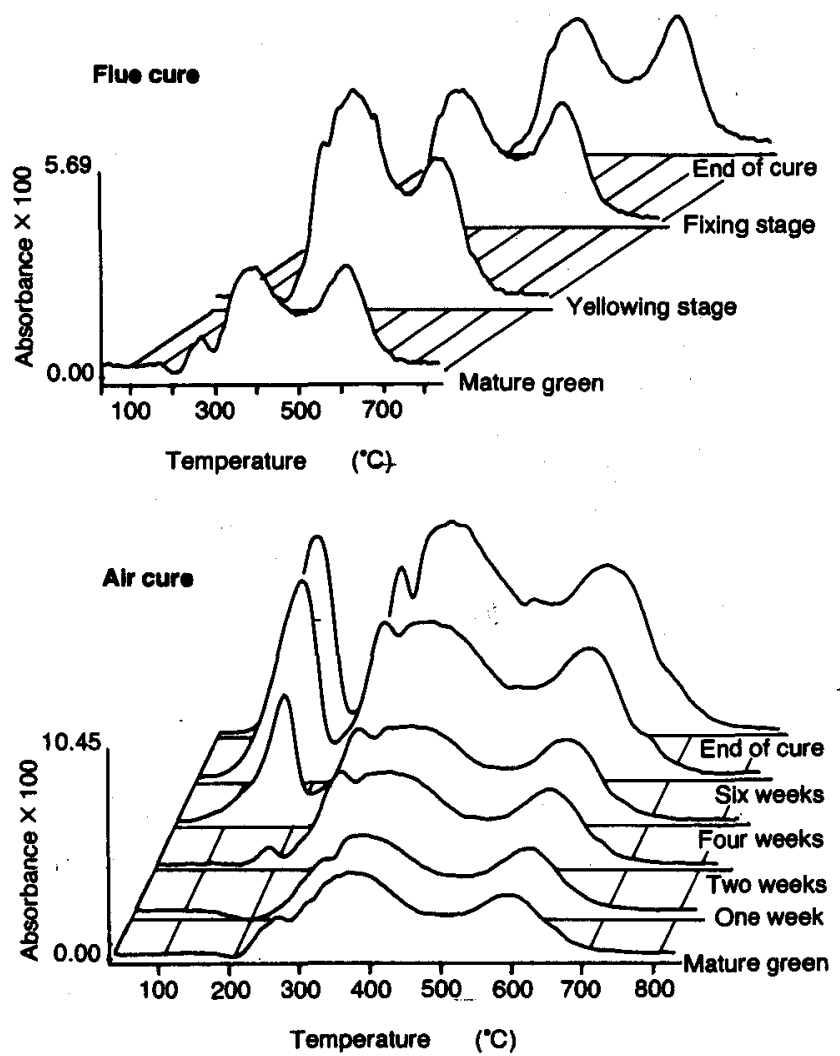

to air curing, the ammonia transitions associated with the amino acids are also observed to increase. In contrast to flue curing, these materials appear to remain in significant quantity throughout most of the treatment - at least on a per gram basis. Studies of Burley tobacco indicate that proteolysis serves as the initial source of amino acids during air curing, but becomes negligible after approximately one week (6). Respiration has been proposed to account for the continued high levels of these constituents thereafter (7). Based on the ammonia profiles, there is no evidence to contradict this explanation for the air-cured bright tobacco as well.

The ammonia below $200^{\circ} \mathrm{C}$ is of interest. It is evident from this study of air-cured bright tobacco that the precursors involved begin to accumulate in the leaf after about two weeks of curing. Literature sources indicate that "free ammonia" is an active species prior to and during this period of time (8). It appears to be derived almost exclusively from the deamination of amino acids which are plentiful as a result of proteolysis. Once formed, this ammonia may be translocated, volatilized, accumulated in the leaf or involved in the synthesis of new compounds. Frankenburg et al. (9), in the study of air-cured cigar tobacco, proposed that a large portion of the ammonia reacted with hydroxy or keto acids to form new amino acids. Hamizton und Lowe (10) made similar observations with Burley tobacco. They proposed further that ammonia was consumed almost totally by these reactions in the early stages of air curing but accumulated later because release exceeded the demands of biosynthesis. The sequence of changes in the ammonia profiles of the air-cured bright tobacco, in particular the appearance of the $190^{\circ} \mathrm{C}$ transition, fits the description of Hamriton and LowE. An imbalance between the rates of deamination and amino acid biosynthesis apparently begins at about two weeks of curing. Excess ammonia then starts to accumulate in the leaf, becoming fixed in the form of the $190^{\circ} \mathrm{C}$ precursor(s). Since amino acid synthesis is a more complex process, it may be slower and eventually surpassed by the simpler deamination reactions with time. However, being more complex, synthesis could also be more easily disrupted. This might occur through deactivation of the necessary enzyme systems due to desiccation or by the loss of other reactants utilized in synthesis. If we digress to the preceding discussion of carbohydrates, it is interesting that the appearance of ammonia at $190^{\circ} \mathrm{C}$ is nearly coincident in time with the disappearance of free sugar pyrolysis product. While this may be purely circumstantial, the data imply that the availability of free sugars is a limiting factor in amino acid synthesis during air curing.

The ability of sugars to control or limit amino acid levels can be clarified by considering the role of glucose in intermediate metabolism. Glucose is a primary metabolite in the parallel but separate pathways of anabolism and catabolism. Through anabolic reactions it can serve as an immediate precursor for the synthesis of polysaccharides. Simultaneously, it may enter catabolic 
pathways where it is converted to simpler molecules through a series of enzymatic reactions. It is in this second process through the tricarboxylic acid cycle that glucose eventually leads to the formation of keto acids. These materials can then react with ammonia to form amino acids.

Starch is enzymatically degraded to provide glucose during curing but it is a limited resource. Thus, after their initial increase from proteolysis, amino acids could remain at significant levels during air curing because free sugars support their synthesis through the formation of keto acids. Ammonia from deamination is essentially being recycled by reacting with these materials. Once the source of sugars (starch) begins to be depleted, less of the keto acids are eventually formed and biosynthesis may start to lag behind deamination. As a consequence, ammonia is not totally utilized and is available for other interactions. Other processes such as the breakdown of insoluble protein could also be a contributing factor to the prolonged higher levels of amino acids.

An additional question which must be considered is the lack of ammonia / amino acid relationships in flue curing. Though the factors involved may be many, all are probably related to the high temperatures employed in this accelerated form of curing. Results indicate that proteolysis does occur and further that deamination is an active process. The ammonia formed from these reactions, however, is probably lost through volatilization as a result of the high temperature used in this curing. Secondly, if free sugars are required, the enzymes necessary to carry them through metabolic reactions to keto acids are probably deactivated, particularly during fixing. Either of these factors alone would likely be sufficient to inhibit the biosynthesis of amino acids.

\section{REFERENCES}

1. Lephardt, J. O., and R. A. Fenner: Characterization of pyrolysis and combustion of complex systems using Fourier transform infrared spectroscopy; Appl. Spectrosc. 34 (1980) 174-185.

2. Lephardt, J. O., and R. A. Fenner: Fourier transform infrared evolved gas analysis - Additional considerations and options; Appl. Spectrosc. 35 (1980) 95-101.

3. Lephardt, J. O.: Fourier transform infrared evolved gas analysis (FT-IR-EGA); Appl. Spectrosc. Rev. 18 (1982-3) 265-303.
4. Amin, A. N., R. C. Long and W. W. Weeks: Transformations of chemical constituents during flue curing of Nicotiana tabacum L., 2. Metabolism of nitrogenous and related constituents; J. Agric. Food Chem. 28 (1980) 656-660.

5. Mohapatra, S. C., and W. H. Johnson: Post-harvest physiology of bright leaf tobacco, 1. Comparative biochemical changes during the yellowing and drying phases of curing; Tob. Sci. 24 (1980) 37-39.

6. Frankenburg, W. G.: Chemical conversions in harvested tobacco leaves; Tob. Int. (N.Y.) 142, No. 13 (1956) 10-14.

7. Palmer, J. K.: Changes in the nitrogenous constituents of Burley tobacco during curing and aging; Tob. Sci. 7 (1963) 93-96.

8. Young, J. R., and R. N. Jeffrey: Changes in certain water-soluble nitrogenous constituents of Burley tobacco during curing; Plant Physiol. (Bethesda) 18 (1943) 433-448.

9. Frankeriburg, W. G., A. M. Gottscho, A. A. Vaitekunas and $R$. Zacharius: The effect of drying and fermentation on the nitrogen compounds in cigar tobacco leaves; Proc. 1st Int. Sci. Tob. Congr., Paris - Bergerac, 1955, pp. 426-431.

10. Hamilton, J. L., and R. H. Lowe: Changes in the concentration of proteins, amino acids and ammonia in Burley tobacco during air curing; Tob. Sci. 22 (1978) 89-93.

\section{Acknowledgements}

The autbors express their appreciation to the following people at Philip Morris Researcb Center for their assistance in this work: Mrs. G. Nixon, Mr. R. Bass, and Mr. G. Newell.

Authors' address:

Pbilip Morris Researcb Center,

P.O. Box 26583,

Richmond, Virginia, 23261, U.S.A. 